\title{
Kegiatan Katalogisasi dalam Pengolahan Koleksi DVD Film di Kepustakaan PDDI LIPI Kawasan Bandung
}

\author{
Reza Eka Puspita ${ }^{1^{*}}$; Samson $\mathrm{CMS}^{2}$; \\ Prodi Ilmu Informasi dan Perpustakaan, Universitas Padjadjaran \\ *Korespondensi: reza16004@mail.unpad.ac.id
}

\begin{abstract}
Cataloging is one of the important activities in the library in order to process library or collection materials. The purpose of this paper is to find out how to process library material the DVD Film collection in Kepustakaan PDDI LIPI Kawasan Bandung. There are several differences in how library materials are processed by Kepustakaan PDDI LIPI Kawasan Bandung, because they use the Resource Descripction and Access (RDA) cataloging guidelines and use the Universal Decimal Access (UDC) classification guidelines. The research method used is descriptive qualitative method that explores and knows the process of cataloging activities. The cataloging process by Kepustakaan PDDI LIPI Kawasan Bandung namely; 1) Completion of RDA Form 2) Validation of RDA Form 3) Data Entry to the Inlislite System. In addition to the different cataloging systems, the library automation system used is also different. The automation system used is the latest version of the initiative developed by Perpustakaan Nasional Republik Indonesia. Cataloging activities of DVD movie collections using RDA guidelines, are very good because the guidelines and systems that have been supported to keep abreast of technology and information. In addition, it can facilitate users in information retrieval.
\end{abstract}

\section{Abstrak}

Katalogisasi merupakan salah satu kegiatan yang penting dilakukan di perpustakaan dalam rangka untuk mengolah bahan pustaka atau koleksi. Tujuan dari penulisan ini adalah untuk mengetahui bagaimana rangakaian cara pengolahan bahan pustaka koleksi DVD Film di 
Kepustakaan PDDI LIPI Kawasan Bandung. Terdapat beberapa perbedaan cara pengolahan bahan pustaka yang dilakukan oleh Kepustakaan PDDI LIPI Kawasan Bandung, karena memakai pedoman katalogisasi Resource Descripction and Access (RDA) dan memakai pedoman klasifikasi Universal Decimal Access (UDC). Metode penelitian yang digunakan adalah metode kualiatif deskriptif yang mengeksplor dan mengetahui proses dari kegiatan katalogisasi. Adapun rangkaian katalogisasi yang dilakukan oleh Kepustakaan PDDI LIPI Kawasan Bandung yaitu ; 1) Pengisian Form RDA 2) Validasi Form RDA 3) Entri Data ke Sistem Inlislite. Selain berbeda sistem katalogisasi, sistem otomasi perpustakaan yang digunakan juga berbeda. Sistem otomasi yang digunakan adalah inlislite versi terbaru yang dikembangkan oleh Perpusnas. Kegiatan katalogisasi koleksi DVD Film menggunakan pedoman RDA, sangat baik karena pedoman dan sistem yang sudah mendukung untuk mengikuti perkembangan teknologi dan informasi. Selain itu, dapat memudahka pengguna dalam temu kembali informasi.

Keywords: Cataloging; Collection Processing; Resource Descripction and Access (RDA).

\section{Pendahuluan}

Perpustakaan merupakan sumber informasi dan sumber pengetahuan bagi para penggunanya. Menurut Pawit M. Yusuf, fungsi utama perpustakaan yaitu sebagai sumber informasi bagi pengguna (Yusuf 2010). Aktivitas dalam perpustakaan yang dilakukan pengguna utamanya adalah pencarian informasi dari bahan pustaka atau koleksi yang terdapat di perpustakaan. Dalam pencarian informasi, pengguna terlebih dahulu mencari letak dari informasi yang dibutuhkan. Untuk memudahkan pengguna dalam mencari koleksi yang dibutuhkan, sebelumnya pengolahan koleksinya harus tepat dan sesuai agar dapat memudahkan temu kembali informasi. Dalam kegiatan pengolahan koleksi perpustakaan, terdapat dua kegiatan yang utamanya dilakukan oleh seluruh perpustakaan yaitu katalogisasi dan klasifikasi. Kegiatan katalogisasi ini menghasilkan katalog yang merupakan data bibliografis dari bahan pustaka atau koleksi.

Katalog akan memudahkan pengguna untuk mencari koleksi dan mengenali bahan pustaka atau koleksi yang dibutuhkan. Seperti yang dikatakan oleh Taylor, katalogisasi ini perlu dilakukan karena merupakan kegiatan penting dalam pengawasan bibliografi (informasi tentang bahan 
pustaka) yang bertujuan untuk memberikan kemudahan temu kembali bahan pustaka (Taylor 2004). Menurut Suwarno, hal itu dapat dimanfaatkan seoptimal mungkin oleh pemustaka (Suwarno 2010). Kegiatan katalogisasi menghasilkan kartu katalog yang berisi informasi bahan pustaka. Dalam era perkembangan teknologi, kegiatan katalogisasi juga ikut berkembang. Dalam perkembangan ini, kegiatan katalogisasi sudah menggunakan komputer dan jaringan internet untuk mendukung prosesnya.

Perpustakaan Pusat Data dan Dokumentasi (PDDI) Kawasan Bandung yang dinaungi oleh Lembaga Ilmu Pengetahuan Indonesia (LIPI) merupakan salah satu perpustakaan khusus yang juga melakukan katalogisasi dalam pengolahan koleksinya. Kegiatan katalogisasi di Kepustakaan PDDI LIPI Kawasan Bandung sudah menggunakan teknologi dalam prosesnya. Koleksi yang akan diolah sebagian besar adalah koleksi elektronik DVD Film, karena Kepustakaan PDDI LIPI Kawasan Bandung terfokus pada pengadaan dan pengembangan koleksi elektronik dan digital untuk menyeimbangi perkembangan teknologi saat ini. Kegiatan katalogisasi yang dilakukan menggunakan pedoman RDA (Resource Descripction and Access) yang merupakan pengembangan dari pedoman katalogisasi sebelumnya yaitu AACR2 (Anglo American Cataloging Rule 2). Belum banyak perpustakaan yang menggunakan pedoman RDA (Resource Descripction and Access) karena prosesnya yang lebih banyak dibandingkan dengan AACR2 (Anglo American Cataloging Rule 2). Hal itulah yang mebuat perpustakaan ini menarik untuk dibahas dan diketahui mengenai proses dalam kegiatan katalogiasi dalam pengolahan koleksi DVD Film yang dimiliki oleh Kepustakaan PDDI LIPI Kawasan Bandung.

\section{Tinjauan Pustaka}

\section{Pengertian Perpustakaan Khusus}

Perpustakaan khusus adalah perpustakaan yang dinaungi oleh sebuah institusi. Baik dari pemerintahan, organisasi masyarakat maupun milik swasta. Adapun menurut Undang - Undang No. 43 Tahun 2007 
tentang perpustakaan yang mendefinisikan perpustakaan khusus sebagai perpustakaan yang diperuntukkan secara terbatas bagi pemustaka di lingkungan lembaga pemerintah, lembaga masyarakat, lembaga pemerintah, lembaga pendidikan keagamaan, rumah ibadah dan organisasi lain. Menurut Sulistyo Basuki, perpustakaan khusus merupakan perpustakaan departemen, lembaga negara, lembaga penulisan, organisasi masaa, militer, industri, maupun perusahaan swasta (Basuki 1993).

Pengolahan Koleksi

Pengolahan koleksi merupakan salah satu tahapan yang ada dalam pengelolaan koleksi di perpustakaan. Pengolahan koleksi merupakan tahapan yang penting dimana koleksi diidentifikasi agar mudah ditemukan oleh pengguna. Pengolahan koleksi adalah tahapan setelah pengadaan koleksi di perpustakaan. Menurut sutarno, terdapat beberapa prinsip pengolahan koleksi yaitu:

a. Mempermudah pengaturan, penataan, dan penempatan

b. Membantu penelusuran oleh pemakai

c. Tersedianya sarana penelusuran

d. Teridentifikasinya semua koleksi dengan rapi dan baik

e. Terpenuhinya informasi sebagai kelengkapan sumber informasi, seperti label, nomor panggil, dan kartu - kartu katalog yang dijajarkan menurut sistem tertentu.

f. Konsistensi penggunaan standar pengolahan sehingga mudah dijadikan pedoman lebih lanjut, artinya tidak mudah berubah, yang berakibat timbulnya kesulitan pada waktu yang akan datang. Pengolahan meliputi pekerjaan:

1. Membuat identifikasi informasi

2. Katalogisasi

3. Klasifikasi

4. Pembuatan Kelengkapan Koleksi

5. Penyusunan Koleksi

6. Pengolahan dengan computer (N.S 2006) 


\section{Katalogisasi}

Katalogisasi atau yang disebut pengkatalogan (cataloguing catalogieseren) merupakan salah satu kegiatan yang termasuk dalam pengolahan koleksi perpustakaan. Secar harfiah, katalogisasi dapat diartikan dengan proses pembuatan daftar keterangan lengkap suatu koleksi yang disusun berdasarkan aturan tertentu (Rahayuningsih 2007). Menurut Taylor, katalogisasi adalah proses mendeskripsikan suatu informasi (bahan pustaka), yang meliputi memilih titik akses nama dan judul, melakukan analisis subyek, menentukan tajuk subyek, dan nomor klasifikasinya (Taylor 2004). Sutarno, juga mengemukakan bahwa katalogisasi merupakan proses pembuatan data bibliografi bahan pustaka berdasarkan suatu peraturan tertentu, dan hasil akhirnya merupakan kartu katalog (N.S 2006). Pada dasarnya katalog dibagi menjadi tiga macam yaitu:

a. Katalogisasi sederhana, yaitu katalogisasi yang hanya menyantumkan informasi data bibliografis, tingkat I berdasarkan Anglo American Cataloging Rules (AACR) II yaitu ; judul asli, pengarang, edisi, penerbit, tempat terbit, dan nomor standar seperti International Standard Book Number (ISBN)

b. Katalogisasi Kompleks, merupakan katalogisasi yang menyantumkan informasi data bibliografis tingkat I ditambah judul parallel, judul-judul seri, judul terjemah, dan pengarang utama.

c. Katalogisasi salinan merupakan kegiatan penyalinan data bibliografi bahan pustaka dengan atau penambahan data yang diperlukan.

\section{Resources Description and Access (RDA)}

RDA dikembangkan oleh Joint Steering Committee (JSC) for Development of RDA yang merupakan representasi dari American Library Association, Australian Committee on Cataloguing, British Library, Canadia Committee on Cataloguing, Chartered Institute of Library and Information Professionals, dan Library of Congress. Sedangkan badan yang mensupervisi proyek pengembangan RDA secara keseluruhan adalah The Committee of 
Principals $(\mathrm{CoP})$ yang terdiri dari institusi-institusi tersebut di atas plus Library and Archives Canada. Proyek ini juga melibatkan Co-Publishers, yakni American Library Association, Canadian Library Association, dan Chartered Institute of Library and Information Professionals yang bertugas memberikan dukungan untuk masalah finansial dan produksi.

Kemunculan RDA didorong oleh adanya fakta bahwa perpustakaan kini beroperasi dalam dunia digital dan berbasis web yang membuat hubungan antara pembuat metadata dan pengguna di luar perpustakaan menjadi semakin penting. Oleh karena itu, pengembangan RDA dilakukan secara kolaboratif dan melibatkan banyak pihak, antara lain, Dublin Core dan komunitas web semantik untuk membandingkan model konseptual dan standar yang digunakan, Library of Congress Network Development and MARC Standards Office untuk memastikan kompatibilitas RDA dengan MARC21, IFLA Cataloguing Section untuk menjamin harmonisasi RDA dengan standar pengatalogan internasional, dan komunitas penerbitan yang telah memiliki daftar terminologi alat berdasarkan standar ONIX yang digunakan untuk dunia penerbitan maupun perpustakaan.

RDA disusun berdasarkan prinsip dan standar internasional yang dikembangkan oleh IFLA, yakni the International Cataloguing Principles (ICP). ICP merupakan pembaruan dari 'Paris Principles' yang merupakan landasan AACR2. Selain itu, RDA juga mengadopsi model konseptual Functional Requirements for Bibliographic Records (FRBR) dan Functional Requirements for Authority Data (FRAD) serta International Standard for Bibliographic Description (ISBD). (Hardi 2011)

\section{Metode}

Metode yang digunakan dalam penelitian ini yaitu metode penelitian kualitatif deskriptif. Menurut Djam'an Satori, mengungkapkan bahwa kualitatif bahwa penelitian kualitatif dilakukan karena peneliti ingin mengeksplor fenomena-fenomena yang tidak dapat dikkuantifikasikan yang bersifat deskriptif seperti proses suatu langkah kerja, formula suatu resep, pengertian - pengertian tentang suatu konsep yang beragam, karakteristik 
suatu barang dan jasa, gambar - gambar, gaya - gaya, tata cara suatu budaya, model fisik suatu artifak dan lain sebagainya (Satori 2013).

Adapun Sugiyono, juga menjabarkan bahwa penelitian kualitatif sebagai metode penelitian yang berlandaskan pada filsafat postpositivisme, digunakan untuk meneliti pada kondisi objek alamiah, dimana peneliti adalah sebagai instrument kunci, teknik pengumpulan data dengan triangulasi, analisis data bersifat induktif atau kualitatif, dan hasil penelitian kualitatif leih menekankan makna daripada generalisasi (Sugiyono 2012).

Dari kedua pernyataan ahli di atas, dapat ditarik kesimpulan bahwa penelitian deskriptif kualitatif adalah proses memperoleh data yang seusia dengan kondisi dan apa adanya yang menekankan pada makna. Penelitian ini, menggunakan metode penelitian deskriptif kualitatif karena penelitian ini mengeksplor proses katalogisasi koleksi film di Kepustakaan PDDI LIPI Kawasan Bandung. Sumber data juga diperoleh dari hasil wawancara terhadap pustakawan dan petugas perpustakaan.

\section{Hasil dan Pembahasan}

Kegiatan katalogisasi dalam pengolahan koleksi DVD film berbasis Resource Description and Access (RDA) di Kepustakaan PDDI LIPI Kawasan Bandung, tidak hanya melewati satu tahapan tetapi melewati beberapa tahapan baik secara konvensional maupun online. Berikut penjabaran tahapan kegiatan katalogisasi:

\section{Tabel 1. Tahapan Kegiatan Katalogisasi}

\begin{tabular}{cc}
\hline Tahapan Kegiatan & \multicolumn{1}{c}{ Rincian Kegiatan } \\
\hline Pengisian Form RDA & - Menentukan subjek dari koleksi film yang akan \\
& di entri datanya. \\
& - Melengkapi kolom - kolom form RDA yang \\
& telah disediakan. \\
& - Menentukan nomor klasifikasi UDC \\
\hline
\end{tabular}




\begin{tabular}{ll}
\hline \multicolumn{1}{c}{ Tahapan Kegiatan } & \multicolumn{1}{c}{ Rincian Kegiatan } \\
\hline Validasi form & - Memeriksa kelengkapan form yang telah diisi \\
& dengan rincian koleksi film \\
& - Memvalidasi form katalog yang sudah sesuai. \\
\hline Entri Data Form RDA & $\begin{array}{l}\text { - Penginputan data form katalog ke dalam } \\
\text { aplikasi inlislite }\end{array}$ \\
\hline
\end{tabular}

Tahapan kegiatan diatas merupakan prosedur katalogisasi dan tahapan yang saling berhubungan satu sama lain. Berikut merupakan penjelasan rincian kegiatan dari tahapan-tahapan kegiatan yang sudah disebutkan, yaitu:

\section{Pengisian Form Katalog RDA}

1. Menentukan subjek koleksi film

Menentukan subjek dari koleksi film adalah tahapan yang mengawali bagian dari proses katalogisasi. Kegiatan ini dilakukan dengan menonton keseluruhan film dan membaca sinopsis yang tertera di bagian belakang kemasan koleksi film. Penentuan subjek film ini tidak hanya dilakukan satu kali tetapi bisa beberapa kali menonton film yang sama untuk mendapatkan subjek yang tepat dan mewakili isi dari koleksi film tersebut.

Kegiatan menentukan subjek ini akan menguras waktu karena satu film bisa ditonton berulang kali tidak seperti koleksi buku atau koleksi tercetak lain yang dapat dibaca sekali dan mendapatkan inti dan menjadi sebuah subjek. Proses penentuan subjek ini membutuhkan ketelitian dan kesabaran yang baik karena prosesnya yang panjang bergantung pada durasi film dan jalan cerita film untuk mendapatkan subjek yang paling tepat.

2. Melengkapi kolom - kolom form RDA

Proses ini merupakan proses kedua setelah mengidentifikasi subjek dari koleksi film. Dalam form katalog ini terdiri dari beberapa kolom yang harus dilengkapi sesuai dengan kebijakan dan kesepakatan pustakawan di Kepustakaan PDDI LIPI Kawasan Bandung yang melakukan kegiatan pengolahan koleksi. Dalam pengisian form, terdapat beberapa kolom atau 
entitas yang sudah dipilih karena kebijakan dan kesepakatan yang dibuat oleh Kepustakaan PDDI LIPI Kawasan Bandung sesuai dengan kebutuhan dan pengolahan koleksi. Alasan lain juga dikarenakan, koleksi yang diproses adalah koleksi film sehingga kolom - kolom form yang diisi tertentu saja. Berikut penjabaran kolom yang dilengkapi dalam form katalog pemroresan koleksi DVD film:

\section{Tabel 2. Form RDA Untuk Katalogisasi}

\begin{tabular}{|c|c|c|}
\hline Field & RDA Element & Keterangan \\
\hline $020(\mathrm{R})$ & Penomoran Standar & $\begin{array}{l}\text { Penomoran standar yang sudah ditentukan } \\
\text { International Standard Audiovisual } \\
\text { Number (ISAN) }\end{array}$ \\
\hline 040 (NR) & Sumber Pengkatalogan & $\begin{array}{l}\text { Diisi dengan sumber atau tempat } \\
\text { pengkatalogan dengan kode “JBPKBJI" }\end{array}$ \\
\hline 043 (NR) & Kode Bahasa & $\begin{array}{l}\text { Diisi dengan kode bahasa sesuai dengan } \\
\text { bahasa film. }\end{array}$ \\
\hline $082(\mathrm{NR})$ & $\begin{array}{l}\text { Nomor Panggilan Desimal } \\
\text { (UDC) }\end{array}$ & $\begin{array}{l}\text { Diisi dengan nomor klasifikasi UDC sesuai } \\
\text { dengan tajuk subjek. }\end{array}$ \\
\hline $110(\mathrm{NR})$ & Kreator (Badan Korporasi) & $\begin{array}{l}\text { Diisi dengan badan atau lembaga yang } \\
\text { membuat film }\end{array}$ \\
\hline 245 (NR) & $\begin{array}{l}\text { Judul dan Keterangan } \\
\text { Penanggung Jawab }\end{array}$ & $\begin{array}{l}\text { Diisi dengan judul film dan keterangan } \\
\text { lembaga yang membuat. }\end{array}$ \\
\hline $250(\mathrm{NR})$ & Pernyataan Edisi & Diisi dengan edisi film jika tersedia. \\
\hline $264(\mathrm{R})$ & $\begin{array}{l}\text { Publikasi (Penerbit/ } \\
\text { Distributor/Produksi/Hak } \\
\text { Cipta) }\end{array}$ & $\begin{array}{l}\text { Diisi dengan nama lembaga penerbit/ } \\
\text { distributor/produser dari film. }\end{array}$ \\
\hline $300(\mathrm{R})$ & $\begin{array}{l}\text { Deskripsi fisik (Jangkauan, } \\
\text { Ilustrasi, Dimensi) }\end{array}$ & $\begin{array}{l}\text { Diisi dengan deskripsi warna, dimensi } \\
\text { film, jenis cakram dan durasi film. }\end{array}$ \\
\hline $336(\mathrm{R})$ & Jenis Isi & $\begin{array}{l}\text { Diisi dengan pernyataan "Citra bergerak } \\
\text { dua dimensi " }\end{array}$ \\
\hline $337(\mathrm{R})$ & Jenis Media & Diisi dengan jenis media yaitu Video \\
\hline $338(\mathrm{R})$ & Jenis Wadah & $\begin{array}{l}\text { Diisi dengan jenis wadah dari film yaitu } \\
\text { Cakram Video }\end{array}$ \\
\hline $520(\mathrm{NR})$ & Catatan Ringkasan & Diisi dengan ringkasan dari isi film. \\
\hline $542(\mathrm{R})$ & Catatan Informasi Hak Cipta & $\begin{array}{l}\text { Diisi dengan "Hak Cipta Pengarang" dan } \\
\text { "Hak Cipta Penerbit" }\end{array}$ \\
\hline
\end{tabular}




\begin{tabular}{cll}
\hline Field & \multicolumn{1}{c}{ RDA Element } & \multicolumn{1}{c}{ Keterangan } \\
\hline $650(\mathrm{R})$ & Subjek (topik) & $\begin{array}{l}\text { Diisi dengan tajuk subjek yang sesuai } \\
\text { dengan isi film. Minimal mencantumkan } \\
\text { tiga subjek terkait dengan isi film. }\end{array}$ \\
\hline $651(\mathrm{R})$ & Subjek (Nama Geografis) & $\begin{array}{l}\text { Diisi dengan letak geografis sesuai dengan } \\
\text { lokasi isi film. }\end{array}$ \\
\hline $700(\mathrm{R})$ & Kontributor (Nama Orang) & $\begin{array}{l}\text { Diisi dengan keseluruhan nama orang } \\
\text { yang berkontribusi di dalam film tersebut. }\end{array}$ \\
\hline $710(\mathrm{R})$ & Kontributor (Badan & $\begin{array}{l}\text { Diisi dengan lembaga yang ikut } \\
\text { berpartisipasi dalam film tersebut. }\end{array}$ \\
\hline $850(\mathrm{R})$ & Korporasi) & $\begin{array}{l}\text { Diisi dengan "Kepustakaan Kawasan } \\
\text { Bandung" }\end{array}$ \\
\hline $856(\mathrm{R})$ & Akses dan Lokasi Elektronik & $\begin{array}{l}\text { Diisi dengan alamat akses elektronik } \\
\text { koleksi film yaitu “digilib.bit.lipi.go.id/sme" }\end{array}$ \\
\hline $990(\mathrm{R})$ & Nomor Induk & $\begin{array}{l}\text { Diisi dengan nomor induk koleksi film } \\
\text { sesuai urutan yang diberikan staff. }\end{array}$ \\
\hline
\end{tabular}

3. Menentukan nomor klasifikasi dengan Universal Decimal Classification (UDC)

Setelah melakukan kedua tahap awal, dilakukanlah untuk menentukan penomoran klasifikasi UDC dengan melihat tajuk subjek yang sudah ditentukan sebelumnya. Menggunakan indeks klasifikasi UDC, dapat mencari subjek yang dituju penomorannya untuk selanjutnya dicari pada pedoman klasifikasi UDC. Dalam pencarian nomor klasifikasi ini, yang memenuhi adalah tajuk subjek yang spesifik sehingga nomor klasifikasi yang didapatkan adalah nomor klasifikasi istilah utama dari film. Karena memakai pedoman UDC, sehingga nomor klasifikasi subjek pendukung dapat ditambahkan di belakang nomor klasifikasi utama dengan simbol titik dua (:). Jika ada keterangan tempat dan jenis media juga dapat ditambahkan setelah subjek tambahan dengan tanda kurung ().

Dalam kegiatan klasifikasi ini, kuncinya adalah dari langkah pertama yaitu penentuan subjek harus tepat dan sesuai dengan isi dari film. Kepustakaan PDDI LIPI Kawasan Bandung memiliki alasan mengapa mereka menggunakan UDC karena, tajuk subjek dalam film itu cukup spesifik hingga ke media yang digunakan sehingga, UDC dianggap paling tepat 
untuk menjadi pedoman klasifikasi untuk koleksi DVD film. Tajuk subjek yang utama tidak harus panjang, namun dapat mewakili keseluruhan isi film, sehingga penomoran klasifikasinya menjadi singkat dan tepat. Subjek tambahan, letak geografis dan jenis media juga dicantumkan agar spesifik.

\section{Validasi Form Katalog RDA}

Sebelum dilakukan entri data ke dalam sistem secara online, perlu dilakukan oleh validasi dan pengecekan ulang isi dari form. Pengecekan ini bertujuan agar informasi yang dimasukkan ke dalam kolom - kolom form katalog sudah benar sesuai dengan deskripsi film. Sesuai dengan ketentuan yang berlaku, jika masih belum tepat harus diperbaiki lagi kemudian divalidasi lagi sampai benar - benar tepat. Ketika informasi dalam kolom - kolom form sudah tepat, maka Pustakawan Madya, sebagai petugas yang memvalidasi akan memberikan tanda tangan pada form dan masuk ke tahap selanjutnya yaitu entri data secara online dengan sistem inlislite.

\section{Entri Data Form Katalogisasi ke dalam Inlislite (Integrated Library System)}

Langkah terakhir dalam kegiatan katalogisasi koleksi DVD film berbasis RDA ini adalah menginput atau memasukkan data dari hasil entri pada form katalog ke aplikasi Inlislite. Kepustakaan PDDI LIPI Kawasan Bandung menggunakan inlinslite ini sebagai sistem otomasi perpustakaan. Inlislite (Integrated Library System) merupakan perangkat lunak yang diciptakan dan dikembangkan oleh Perpustakaan Nasional Republik Indonesia (Perpusnas) pada tahun 2011.

Proses penginputan data katalog dilakukan dengan membuka situs yang telah disediakan. Setelah terbuka, tampilan utama inlislite backoffice serta terdapat informasi log in ke dalam sistem menggunakan username dan password. Setelah melakukan $\log$ in, tampilan selanjutnya adalah informasi mengenai data statistic koleksi yang sudah diinput datanya ke dalam sistem inlislite serta data kunjungan yang terintegrasi dengan komputer pengunjung. Untuk melakukan entri data katalog, klik katalog di sisi kiri untuk menampilkan form katalog online. Setelah memilih entri katalog 
RDA dan muncul data bibliografis, langkah selanjutnya memasukkan data form katalog yang sudah dibuat manual dan divalidasi sebelumnya dan memindahkannya sesuai dengan field. Jika field yang akan diisi tidak tersedia di form online, maka harus menambahkan tag yang berada di bawah tulisan "Data Bibliografis".

Setelah semua data yang berada pada form sebelumnya dipindahkan dan diinput ke dalam katalog online dalam inlislite, maka langkah selanjutnya adalah menyimpan data katalog yang sudah diinput dengan menekan "simpan" dan data yang sudah diinput akan otomatis tersimpan dalam database. Setelah disimpan, hasil dari entri data katalog DVD film yang diinput ke dalam database inlislite dan dapat dilihat hasilnya di OPAC. Oleh karena itu, kegiatan katalogisasi ini sangat penting untuk memudahkan pengguna mencari informasi terkait dengan koleksi DVD film di Kepustakaan PDDI LIPI Kawasan Bandung. Walaupun, pada saat entri katalog RDA ini lebih rumit daripada AACR2 namun, hasilnya pengguna dapat lebih mudah mencari informasi dari satu ke yang lain karena dalam sistem ini, mendukung untuk mencari informasi yang berkaitan satu sama lain.

\section{Kesimpulan}

Katalogisasi merupakan salah satu kegiatan yang sangat penting di perpustakaan sebagai entri bibiliografis dan sebagai sarana temu kembali informasi bagi para pengguna. Kegiatan katalogisasi koleksi DVD Film di Kepustakaan PDDI LIPI Kawasan Bandung sangat baik, karena dalam penyelenggaraannya, pedoman dan sistem otomasi yang digunakan sangat mengedepankan kepentingan dari pengguna. Berbeda dengan AACR2, RDA memiliki lebih banyak entri data dan kolom untuk mengisi informasi namun, hal ini bermanfaat untuk temu kembali informasi agar lebih spesifik dalam mencari informasi yang dibutuhkan.

Dalam kegiatan ini, kegiatan katalogisasi koleksi DVD Film banyak memakan waktu selain isi form katalogisasi yang lebih banyak, dari penilihan tajuk subjek film juga memakan waktu karena harus menonton film dan memahami isi film agar dapat menarik subjek. Tetapi, selain kekurangan 
itu kelebihannya adalah informasi dapat lebih mudah dicari dan pedoman dan sistem yang digunakan Kepustakaan PDDI LIPI Kawasan Bandung juga menyeimbangkan dengan perkembangan teknologi informasi yang saat ini digunakan.

\section{Saran dan Ucapan Terimakasih}

Saran yang dapat penulis ajukan adalah dengan menambahkan Sumber Daya Manusia (SDM) yang memenuhi kualifikasi untuk mengolah koleksi khususnya pada kegiatan katalogisasi agar koleksi DVD Film semuanya dapat diakses oleh pengguna.Ucapan Terimakasih disampaikan kepada penulis kepada informan yaitu pustakawan dan para petugas perpustakaan di Kepustakaan PDDI LIPI Kawasan Bandung, karena dengan informasi dan dukungan mereka, penulis dapat menyusun dan menyyelesaikan tulisan ini dengan baik.

\section{Daftar Pustaka}

Basuki, Sulistyo. 1993. Pengantar Ilmu Perpustakaan. Jakarta: Gramedia.

Hardi, Wishnu. 2011. "Mengenal Resource Description \& Access (Rda) Dan Aplikasinya Dalam Dunia Perpustakaan.” Visi Pustaka. Accessed October 29, 2019. http://old.perpusnas.go.id/Attachment/ MajalahOnline/WishnuHardi_Resource_description.pdf

N.S, Sutarno. 2006. Manajemen Perpustakaan: Suatu Pendekatan dan Praktik. Jakarta: Sagung Seto.

Rahayuningsih. 2007. Pengelolaan Perpustakaan. Yogyakarta: Graha Ilmu. Satori, Djam'an. 2013. Metode penelitian kualitatif. Bandung: Alfabeta.

Sugiyono. 2012. Metode Penelitian KuantitatifKualitatif dan R\&D. Bandung: Alfabeta.

Suwarno, Wiji. 2010. Pengetahuan dasar kepustakaan: sisi penting perpustakaan dan pustakawan. Bogor: Ghalia Indonesia.

Taylor, Arlene G. 2004. Wynar's introduction to catalonging and classification Rev. edition. Westport: Libraries Unlimited. 
n.d. "Undang-Undang Republik Indonesia Nomor 43 Tahun 2007 Tentang Perpustakaan." http://www.pnri.go.id/lawdetail.php?lang=id\&id=17 0920114322Ir9g6HhRuc.

Yusuf, Pawit M. 2010. Pedoman Penyelenggaraan Perpustakaan Sekolah. Jakarta: Kencana. 